\title{
EMC 2013
}

\section{2nd European Muscle Conference, Programme and Abstracts, September 21-25, 2013, Felix Meritis, Amsterdam}

\section{Message from the Organisers of the 42nd European Muscle Conference}

Dear colleagues,

Bringing back the heart of muscle research to the Netherlandswhere in 1682 Antoni van Leeuwenhoek discovered the striation pattern in muscle-we are honoured to host the 42nd annual meeting of the European Society for Muscle Research in the city of Amsterdam.

The European Muscle Conference is hosted at Felix Meritis. A renowned center for the promotion of arts and sciences, Felix Meritis first opened its doors in 1788, and is located on one of Amsterdam's characteristic canals, de Keizersgracht.

The EMC is designed to bring together clinicians and researchers with a background in various facets of cardiac, skeletal, and smooth muscle science. Therefore, we have put together an exciting scientific programme that has a strong focus on basic research and its translation to clinical application. Both established and young scientists from all over Europe, the Americas, Asia, and Australia are contributing to the scientific programme. Moreover, exhibitors will show their novel products and will be available for discussions of needs and ideas.

The meeting features poster and platform sessions. The platform sessions highlight emerging topics and provide a platform for young, talented scientists to present their findings.

We look forward to a very exciting and worthwhile five days with you, exploring science of mutual interest and setting a framework for future research discussions.

Welcome to Amsterdam!

Coen Ottenheijm, Department of Physiology, ICaR-VU, VU University Medical Center Amsterdam.

Rob Wüst, Department of Physiology, ICaR-VU, VU University Medical Center Amsterdam.

Richard Jaspers, Laboratory for Myology, MOVE Research Institute Amsterdam, VU University Amsterdam.

Jolanda van der Velden, Department of Physiology, ICaR-VU, VU University Medical Center Amsterdam.

\section{Message from the Organisers of the Young Investigators Symposium of the 42nd European Muscle Conference}

Dear young investigators,

It is a great pleasure to welcome you to the Young Investigators Symposium preceding the European Muscle Conference on Saturday September 21st 2013 in Amsterdam. The EMC meeting has a tradition of over 40 years and this year's programme covers the whole muscle field from skeletal muscle to cardiac and smooth muscle.

The one-day Young Investigators Symposium, which is organised for the first time as an official part of the EMC, closely follows the footstep of the EMC in terms of research interests. Our target audience are the young participants such as undergraduate and graduate students, but also post-docs and early-career investigators. Obviously, we also welcome more experienced researchers and professors to attend the Symposium to interact, stimulate, challenge and inspire the young investigators.

The aim of our Symposium is to stimulate interaction amongst participants, but also to provide hands-on information on how to become successful in the scientific community. Therefore, we appreciate the contribution of Prof David Eisner as well as the panel committee for their contribution to the symposium. They will be very happy to answer all your career-related questions during the panel discussion, as well as during coffee breaks.

We are thankful that our symposium is supported by a Grant from The Physiological Society (United Kingdom) and MEDIA, an FP7-funded European consortium on diastolic heart failure (http://www. diastolicheartfailure.eu).

We are looking forward to seeing you in Amsterdam!

Ilkka Heinonen, Division of Experimental Cardiology, Erasmus University Medical Center Rotterdam.

Josine de Winter, Department of Physiology, ICaR-VU, VUmc, Amsterdam.

Rob Wüst, Department of Physiology, ICaR-VU, VUmc, Amsterdam. 


\section{Programme}

Saturday September 21, 2013

Young Investigators Symposium

\subsection{0 \\ $14.00-14.30$

\author{
Registration \& Coffee/Tea \\ Key Note Lecture by David Eisner-How to \\ succeed in science
}

This talk is designed to stimulate discussion about some of the issues involved in surviving in science. In many countries science is becoming ever more competitive and less secure. Is science still a good career to embark on? Can one combine science with a normal family life? Can one plan a scientific career or need it be left to chance? How do I select a problem to work on? Do I need a mentor? How to survive rejection?

I will illustrate the talk with some personal observations but would strongly recommend everyone to read Advice to a Young Scientist by P. B. Medawar (1980)

David Eisner obtained his undergraduate degree in Cambridge and his D. Phil from Oxford. He spent the period 1980-1990 in the Department of Physiology at University College London as a lecturer. From 1990 to 1999 he was Professor of Veterinary Biology at Liverpool University before moving to Manchester as Professor of Cardiac Physiology in October 1999. He is currently the British Heart Foundation (BHF) Professor of Cardiac Physiology.

His research focuses on the regulation of intracellular calcium in the heart and the link between changes of calcium and those of contractility. He is also interested in the relationship between disturbed calcium signalling and arrhythmias. He is currently Editor-in-Chief of the Journal of Molecular and Cellular Cardiology, and President of the Federation of European Physiological Societies.

\subsection{0-15.30 Plenary discussion and Q\&A with senior principal investigators \\ Moderator: Rob Wüst \\ Prof David Eisner, Institute of Cardiovascular Sciences, University of Manchester, UK \\ Prof Karin R. Sipido, Division of Experimental Cardiology, KU Leuven, Belgium \\ Prof Jil C. Tardiff, Department of Cellular and Molecular Medicine, University of Arizona, USA \\ Prof Pieter P. de Tombe, Department of Cell and Molecular Physiology, Loyola University Chicago, USA}

15.30-16.00 Coffee break

16.00-17.00 Three 10-min presentations from young investigators

Chairs: Ilkka Heinonen and Josine de Winter

16.00-16.20 Marion Pauly: Pharmacological AMPK-activation improves skeletal muscle mitochondrial function and muscle endurance in aged myostatin ko mice.

16.20-16.40 Johan Lindqvist: Viral gene delivery restores muscle function in a mouse model of nemaline myopathy.

16.40-17.00 Anna Müller: Exercise modifies titin phosphorylation and reduces cardiac myofilament stiffness.
This symposium is supported by The Physiological Society (United Kingdom) and MEDIA, an FP7-funded European consortium on diastolic heart failure (http://www.diastolicheartfailure.eu):

\section{Programme}

Saturday September 21, 2013

\subsection{0-19.00 Registration \& \\ Drinks \& Snacks (famous 'bitterballen') for the 'Young \& Old' investigators.}

\subsection{0-20.00 Key Note Lecture}

Dick Swaab: Brain and exercise

Dick Swaab earned his medical and doctoral degrees at the University of Amsterdam, where he became involved in brain research during his third year of medical school. From 1978 until 2005 he has served as director of the Netherlands Institute for Brain Research and since 1979 as Professor of Neurobiology at the medical faculty of his alma mater. He is leader of the research group on Neuropsychiatric Disorders in the Netherlands Institute for Neuroscience. Dick Swaab also holds 3 guest professorships in China, and the USA, is appointed for 2011-2014 Chao Kuang Piu Chair of Zhejiang University, Hangzhou, P. R. China and is "Companion in the Order of the Dutch Lion", bestowed by her Royal Majesty Queen Beatrix of The Netherlands. In 2008 Swaab obtained the Academy medal for his role in national and international neuroscience.

His major research interests focus on brain development, sexual differentiation, aging of the brain, Alzheimer's disease, the neurobiological basis of depression and eating disorders. He has published over 520 papers in SCI journals, authored more than 200 chapters in books, and edited 41 books. Dick Swaab mentored $82 \mathrm{PhD}$ students from which 16 are now full professor. He is author of the 2 volume monograph The Human Hypothalamus that appeared in the Handbook of Clinical Neurology series, Elsevier, Amsterdam (1,000 pp) and of the Dutch bestseller We are our Brain, that is translated in German, Chinese, Taiwanese and Italian, and will appear in 8 more languages. A childrens version of the book (You are your brain) has also appeared in Dutch in 2013.

In 1985, Dick Swaab founded the Netherlands Brain Bank (NBB) to serve as a source of clinically and neuropathologically well-documented research tissue. Since its founding, the Brain Bank has provided samples from more than 3,500 autopsies to 500 research groups in 25 countries. He was director of the NBB until 2005.

Sunday September 22, 2013

\subsection{0-08.45 Coffee/Tea}

08.45-09.00 Welcome \& introduction

09.00-11.00 Session I. Mechanotransduction/muscle adaptation Chairs: Troy Hornberger and Richard Jaspers. 
09.00-09.30 Troy Hornberger: The mechanical activation of mTOR signaling: an emerging role for lysosomal targeting. (I.O1.)

09.30-10.00 Shin'ichi Takeda: The molecular mechanism of muscle hypertrophy; roles of $n N O S / N O$, peroxynitrite and

TRPV1.(I.O2.)

10.00-10.15 A. Judge: HDAC1 activates foxo in skeletal muscle and is both sufficient and required for skeletal muscle atrophy. (I.O3.)

10.15-10.30 J. Machado: Calcitonin gene-related peptide (CGRP) inhibits the autophagy-lysosomal system through cAMP/PKA signaling in isolated skeletal muscles. (I.O4.)

10.30-10.45 C. Moorwood: Mechanotransduction via the sarcoglycan complex in skeletal muscle. (I.O5.)

10.45-11.00 R. Piccirillo: The p97/VCP ATPase is critical in muscle atrophy and for the accelerated degradation of most muscle proteins. (I.O6.)

11.00-11.30 Coffee break

11.30-13.00 Session II. Muscle regeneration

Chairs: Fabien Le Grand and Marie-Jose Goumans.

11.30-12.00 Fabien Le Grand: Wnt signaling(s) and skeletal muscle regeneration. (II.O1.)

12.00-12.30 Marie-Jose Goumans: Cardiac progenitor cells for heart repair. (II.O2.)

12.30-12.45 L. Mazelet: Recovery from skeletal muscle paralysis: studies using embryonic zebrafish. (II.O3.)

12.45-13.00 R. Mounier: AMPK $\alpha 1$ regulates macrophage skewing during skeletal muscle regeneration: a link between inflammation and stem cell biology. (II.O4.)

13.00-15.00 Lunch break and poster viewing (Sessions I-IV)

15.00-16.30 Session III. Cardiac muscle disease: right and left Chairs: Walter Paulus and Frances de Man.

15.00-15.30 Walter Paulus: The failing left ventricle: a novel paradigm for heart failure with preserved left ventricular ejection fraction. (III.O1.)

15.30-16.00 Frances de Man: Effect of the pulmonary circulation on the heart. (III.O2.)

16.00-16.15 V. Sala: Sustained Met signalling in the heart leads to cardiac compensated hypertrophy and remodelling, which evolve into congestive heart failure. (III.O3.)

16.15-16.30 F. Suhr: Beta-parvin knockout in mice causes pathological cardiac adaptations towards physiological volume loading. (III.O4.)

16.30-17.00 Coffee break

17.00-18.30 Session IV. Excitation-contraction coupling

Chairs: John Solaro and Pieter de Tombe.

17.00-17.30 Karin Sipido: Electrophysiologic abnormalities in failing cardiac muscle. (IV.O1.)

17.30-18.00 Pieter de Tombe: Frank-Starling mechanism. (IV.O2.)

18.00-18.15 I. Adeniran: In silico investigation of the electromechanical consequences of the short $Q T$ syndrome. (IV.O3.)

18.15-18.30 M. Reconditi: Sarcomere-length dependence of the structure of the thick filament studied by X-ray diffraction from intact frog muscle fibres at rest. (IV.O4.)

18.30-19.30 Sponsor presentations
Monday September 23, 2013

08.30-09.00 Coffee/Tea

09.00-11.00 Session V. Large cytoskeletal proteins

Chairs: Henk Granzier and Coen Ottenheijm.

09.00-09.30 Henk Granzier: Titin and Nebulin: major players in striated muscle function and disease. (V.O1.)

09.30-10.00 Siegfried Labeit: Insights from structural biology into novel titin variant alleles implicated in heart failure. (V.O2.)

10.00-10.15 S. Hunter: A new network crosslinking thick filaments in the bare region in vertebrate striated muscle: titin kinase links? (V.O3.)

10.15-10.30 A. Kho: Titin kinase, maintaining muscle according to demand. (V.O4.)

10.30-10.45 K. Pelin: The spectrum of mutations and normal variation in the nebulin gene. (V.O5.)

10.45-11.00 M. Helmes: Development of a fast and sensitive (nanoN) force transducer for muscle research. (V.O6.)

11.00-11.30 Coffee break

11.30-13.00 Session VI. Diaphragm physiology

Chairs: Leo Heunks and Theodorus Vassilakopoulos.

11.30-12.00 Leo Heunks: The effects of critical illness on respiratory muscle function. (VI.O1.)

12.00-12.30 Theodorus Vassilakopoulos: The respiratory muscles exhibit significant adaptability and plasticity. (VI.O2.)

12.30-12.45 P. Hooijman: Diaphragm muscle fiber strength is severely reduced in mechanically ventilated ICU patients and is restored by a fast troponin activator. (VI.O3.)

12.45-13.00 L. Larsson: Time-course analysis of mechanical ventilation-induced diaphragm contractile muscle dysfunction. (VI.O4.)

13.00-15.00 Lunch break and poster viewing (Sessions V-VIII)

15.00-16.30 Session VII. Muscular dystrophies and congenital myopathies

Chairs: Nigel Clarke and Silvere van der Maarel.

15.00-15.30 Silvere van der Maarel: New developments in facioscapulohumeral muscular dystrophy. (VII.O1.)

15.30-16.00 Nigel Clarke: Recent developments in the congenital myopathies. (VII.O2.)

16.00-16.15 W. Eilers: Trans-splicing aav vectors to deliver fulllength dystrophin in mdx mice. (VII.O3.)

16.15-16.30 C. Latroche: Alterations of the microvascular system in chronic myopathies and functional repercussions on the muscle tissue. (VII.O4.)

16.30-17.00 Coffee break

17.00-18.30 Session VIII. Smooth Muscle

Chairs: Geerten van Nieuw Amerongen and Sarah George.

17.00-17.30 Sarah George: Wnt-signaling in vascular SMCs. (VIII.O1.)

17.30-18.00 Rama Krishnan: Contraction of the airway smooth muscle cell in asthma. (VIII.O2.) 
18.00-18.15 I. Heinonen: Nitric oxide synthase inhibition, with and without inhibition of prostaglandins, reduces blood flow similarly in different human skeletal muscles. (VIII.O3.)

18.15-18.30 E. Konik: Vascular reactivity in pulmonary arterial hypertension (PAH): role of myosin light chain phosphatase and nonmuscle myosin. (VIII.O4.)

18.30-19.00 Business Meeting

Tuesday September 24, 2013

08.30-09.00 Coffee/Tea

09.00-10.30 Point-Counterpoint

$\mathrm{Ca}^{2+}$-perturbations versus Sarcomere dysfunction in cardiac disease. What matters most? Moderator: Karin Sipido. (PC.O1.)

09.00-09.30 David Eisner: Point: $\mathrm{Ca}^{2+}$-perturbations cause cardiac dysfunction.

09.30-10.00 John Solaro: Counterpoint: sarcomeric dysfunction is the cause of cardiac dysfunction (PC.O2.).

10.00-10.30 Discussion between speakers and audience moderated by Karin Sipido.

10.30-11.00 Coffee break

11.00-13.00 Session IX. Mutations in inherited cardiomyopathies Chairs: Tjeerd Germans and Michelle Michels.

11.00-11.30 Carolyn Ho: Sarcomere mutations in hypertrophic cardiomyopathy. (IX.O1.)

11.30-12.00 Yigal Pinto: Role of miRNA in inherited cardiomyopathies. (IX.O2.)

12.00-12.15 J. Montag: The $\beta$-myosin mutation R453C in Familial Hypertrophic Cardiomyopathy leads to altered crossbridge kinetics. (IX.O3.)

12.15-12.30 C. Rowlands: Calcium handling in the ACTC E99 K transgenic mouse model of hypertrophic cardiomyopathy (HCM). (IX.O4.)

12.30-12.45 K. Spaendonck-Zwarts: TTN mutations are common in families with peripartum cardiomyopathy and dilated cardiomyopathy. (IX.O5.)

12.45-13.00 B. Tosi: E163R cardiomyopathy-related cTnT mutation affects $\mathrm{Ca}^{2+}$-regulation and energetics of cardiac myofilaments in a murine model. (IX.O6.)

13.00-15.00 Lunch break and poster viewing (Sessions IX, X, XI and XII)

15.00-17.00 Session X. Regulation of cardiac muscle contraction in health and disease

Chairs: Corrado Poggesi and Diederik Kuster.

15.00-15.30 Samantha Harris: Role of cardiac myosin binding protein $C$ in the heart and effects of haploinsufficiency/phosphorylation. (X.O1.)

15.30-16.00 Jil Tardiff: Mutations in thin filament proteins: current state. (IX.O2.)

16.00-16.15 O. Cazorla: Urban carbon monoxide pollution aggravates heart failure through oxidative stress. (IX.O3.)
16.15-16.30 A. Kovacs: Right ventricular cellular contractile function is altered and differently modified by antiplatelet agents in a rat model of post-ischemic heart failure. (IX.O4.)

16.30-16.45 D. Miranda-Silva: Reverse remodelling in wistar rats after surgical removal of chronic pressure-overload. (IX.O5.)

16.45-17.00 P. Wijnker: Phosphorylation of protein kinase $C$ sites SER42/44 blunts enhanced length-dependent activation in response to protein kinase A. (IX.O6.)

17.30-18.30 Guided tours to Observatory of Felix Meritis

$19.30 \quad$ Evening Social Event Scheepvaartmuseum (Kattenburgerplein 1)

19.30 Drinks and start of guided tour (limited availability)

$20.30 \quad$ Diner

Wednesday September 25, 2013

08.30-09.00 Coffee/Tea

09.00-10.45 Session XI. Muscle physiology: extreme functional demands

Chairs: Willem van der Laarse and Coert Zuurbier.

09.00-09.30 Robert Balaban: Systems biology of muscle mitochondria. (XI.O1.)

09.30-10.00 Andrew Murray: Cardiac and skeletal muscle metabolism in high altitude hypoxia. (XI.O2.)

10.00-10.15 F. Graça: Epinephrine restrains the fasting-induced catabolic effects on skeletal muscle protein breakdown. (XI.O3.)

10.15-10.30 S. Lamon: Acute regulation of the stars signalling pathway in response to endurance and resistance exercise. (XI.O4.)

10.30-10.45 D. Salvadego: Skeletal muscle oxidative function after a 10-day exposure to hypoxia and microgravity. (XI.O5.)

10.45-11.15 Coffee break

11.15-13.00 Session XII. Mitochondrial function in health and disease

Chairs: Ger Stienen and Christoph Maack.

11.15-11.45 Marcella Canton: Contribution of mitochondrial ROS formation to myofibrillar protein oxidation in cardiac and muscle disease. (XII.O1.)

11.45-12.15 Christoph Maack: Regulation of mitochondrial ROS formation in cardiac myocytes. (XII.O2.)

12.15-12.30 J. Fauconnier: TNF $\alpha$-mediated caspase-8 activation induces ROS production and trpm 2 activation in adult ventricular myocytes. (XII.O3.)

12.30-12.45 E. Fowler: Reduced expression of creatine kinase in rat failing right ventricle causes diastolic dysfunction in ventricular myocytes. (XII.O4.)

12.45-13.00 R.C.I. Wüst: NADH and FAD kinetics reveal altered mitochondrial function in right ventricular heart failure. (XII.O5.)

$13.00 \quad$ Awards and Closing Remarks 
Sunday September 22, 2013

\section{Session I. Mechanotransduction/muscle adaptation}

\section{\# Presenter Title}

1 Baán J. The compact mutation of myostatin causes a glycolytic change in the phenotype of skeletal muscles.

2 Ballak S. B. Increased mass rather than specific tension causes the increased force generating capacity in hypertrophied adult and old mouse plantaris muscle.

3 Barnhill E. Quantification of limb neuromuscular activation via viscoelastic property mapping with magnetic resonance elastography.

4 Bartels E. M. Non-invasive assessment of muscle function: acoustic myography re-invented.

5 Barton E. R. Masticatory muscles do not undergo atrophy in space.

6 Bastide B. Effects of a 21 day Bed Rest on the PI3/AKT pathway: role of O-GlcNAc

7 Desplanches D. Treatment with trichostatin A attenuates unloaded-induced skeletal muscle atrophy.

8 Dijk van M. Compared to 10 mo old mice, 24 mo old male c57/bl6 mice show characteristics of sarcopenia and anabolic resistance.

9 Gondin J. Muscle damage after neuromuscular electrostimulation assessed by multimodal magnetic resonance imaging.

10 Flück $\mathrm{M}$. Tenascin-C is quantitatively related to angiotensin-modulated muscle growth in man.

11 Harzer W. Gene expression in masseter muscle after orthognathic surgery in comparison with untreated healthy controls.

12 Juffer P. Fluid shear stress stimulates growth factor expression and nitric oxide production by myotubes.

13 Kanzaki N. Effect of glucosamine-containing supplement on knee pain and locomotor functions in subjects with knee pain.

14 Kocsis $\mathrm{T}$. Changes in the tissue glycogen distribution in a hypermuscular mice model.

15 Kopylova G. V. Study of influence of hyperthyroidism on calcium regulation of muscle contraction in slow and fast skeletal muscle of rabbit with an in vitro motility assay.

16 Kröss M

Cross-bridge attachments in fibre types of human skeletal muscle.

17 Liu J. Age-related changes in neurotrophic factors in human extraocular and limb muscles.

18 Meijer J. P. Differences in contractile properties of single muscle fibres from bodybuilders, wrestlers and untrained controls.

19 Mirzoev T. M. The key markers of proteolytic signaling pathways in $\mathrm{m}$. vastus lateralis among alcohol consumers.
Mithraratne K. Mathematical representation of fascicular orientation in skeletal muscles and its implications on passive and active deformations.

21 Moro T.

Molecular signalling response to short duration high intensity/low volume resistance training in human skeletal muscle.

22 Nemirovskaya C.L.

The effect of calpain inhibition on signaling pathways in m.soleus under hindlimb unloading of rats.

23 Reggiani C.

Effects of endurance training, resistance training and neuromuscular electrical stimulation (NMES) on myonuclei and satellite cells density.

Schöck F.

Alp/enigma family proteins cooperate in Z-disc formation and myofibril assembly.

Shenkman B. S. Signaling effects in reloaded muscle: eccentric-like events.

Silveira W. A. CAMP/PKA signaling activation induces foxo1 phosphorylation and suppresses ubiquitin-proteasome system in skeletal muscle.

27 Stevens L.

Effects of hypo/hypergravity variations on mice soleus plasticity.

28 Suhr F.

Divergent in vivo muscle contractions cause distinct skeletal muscle focal adhesion/ costamere adaptations and related downstream signaling pathways.

Zacharewicz E. Regulation of skeletal muscle micrornas in young and old adults following acute resistance exercise.

30 Zong $\mathrm{H}$.

Suppression of mTORC1 activation in acid$\alpha$-glucosidase deficient disease is ameliorated by leucine supplementation.

\section{Session II. Muscle regeneration}

\section{\# Presenter Title}

1 Akpulat U. Klf5 modulates proliferation and differentiation of myoblasts.

2 Berkholz J.

SkNAC: A multi-functional regulator of myogenesis and skeletal muscle regeneration.

3 Durcan P. J. Do humans and flies share the same molecular mechanisms in regulating muscle cell fusion events?

$4 \quad$ Flück $\mathrm{M}$

Calcium/Calmodulin-dependent kinase preserves contractility of injured skeletal muscle.

5 Gallo S.

HGF receptor agonists protect cardiomyocytes from $\mathrm{CoCl}_{2}$-induced cell injury.

6 Gondin J.

Role of macrophagic HIFS in the resolution of inflammation during skeletal muscle regeneration.

7 Guha R. Deep molecular investigation of skeletal muscle: from satellite cell to muscle tissue 
8 Joshi S Role of tead family of transcription factors in skeletal muscle differentiation.

$9 \quad$ Kocaefe C. SFRP2 designates skeletal muscle fibrosis in immobilized muscle.

10 Jozkowicz A. Overexpression of hemeoxygenase-1 in murine myoblasts stimulates blood flow recovery after ischemia.

11 Naldaiz-Gastesi Murine muscle engineered from N. dermal precursors: an in vitro model for skeletal muscle generation, degeneration and fatty infiltration.

12 Lindström

Pax7 positive/satellite cells in human extraocular muscles.

13 Meijden van der K.

Effects of 1,25-dihydroxyvitamin D on proliferation and differentiation of $\mathrm{C} 2 \mathrm{C} 12$ myoblasts.

14 Myburgh K. H. Significant myogenin expression is not required to synthesise small muscle fibres after in vivo injury in transgenic mice.

15 Pfuhl M. MS1/stars: a novel cardiac stress response transcription factor?

16 Wójtowicz I. Functional analysis of $\alpha \mathrm{B}$-crystallin's ortholog in muscles development and sarcomers stabilisation in Drosophila melanogaster.

Session III. Cardiac muscle disease: right and left

\section{\# Presenter Title}

1 Colman M.A. The role of the pulmonary veins and left atrium in the remodelled human atria during atrial fibrillation.

2 Manders E. Contractile dysfunction of left ventricular cardiomyocytes in patients with pulmonary arterial hypertension.

3 Unger A. Mena/VASP-dependent anchoring of cytoplasmic actin protects against dilated cardiomyopathy.

4 Watanabe D. Changes in myofibrillar $\mathrm{Ca}^{2+}$-sensitivity with low-frequency force depression.

5 Zendzian- Sphingolipid profile in the unifarcted

Piotrowska ventricular wall of the rat after myocardial

M. infarct.

\section{Session IV. Excitation-contraction coupling \\ \# Presenter Title}

1 Adamek N. Temperature and 'fatigue' effects on ATPinduced dissociation of fast and slow actomyosin.

2 Bengtsson E. Studies of actin conformational states related to myosin binding.

3 Bullard B. Similarities in the regulation of insect flight muscle and cardiac muscle of vertebrates.

4 Campbell K. Dynamic coupling of regulated binding sites S.
5

Chung C. S. Low temperature and transmural effects augment variability in measurements of calcium transients and sarcomere length in unloaded left ventricular cardiomyocytes.

6 Degens H. The effects of steady lengthening on force of rat soleus fibres: data to test models of cross-bridge function.

7 Katnelson L. Effect of mechanical factors on the rhythm B. disturbances in cardiomyocytes overloaded with calcium: modeling and experimental validation.

8 Leite F. S. Force produced by thick filaments isolated from soleus muscles lacking arginyl-trnaprotein transferase (Ate1).

9 Papadopoulos The cytoplasmic foot of type 1 ryanodine S. $\quad$ receptor targets junctionally, retrogradely enhances 1-type $\mathrm{Ca}^{2+}$-currents and homotetramerizes.

10 Reconditi M. Temperature dependence of myosin filament structure in relaxed mammalian muscle.

11 Toral-Ojeda I. New evidence for calcium mishandling in human Calpain 3 deficient myotubes.

Monday September 23, 2013

Session V. Large cytoskeletal proteins

\# Presenter Title

1 Anderson Determining the molecular mechanisms that B.R. link a titin mutation to cardiomyopathy.

2 Bobylev A. Study on amyloidogenesis of smooth muscle G. and striated muscle titin in vitro.

3 Buck D

Removal of titin's proximal Ig domains results in differential splicing of titin and alters skeletal muscle function.

4 Chung C. S. Shortening of the proximal tandem Ig segment of titin leads to diastolic dysfunction.

5 Franssen C. Myocardial titin hypophosphorylation importantly contributes to heart failure with preserved ejection fraction in a rat cardiometabolic risk model.

$6 \quad$ Kötter S

Human myocytes are protected from stressinduced stiffening by chaperone binding to titin spring elements.

7 Leber $\mathrm{Y}$. Filamin $\mathrm{C}$ is a highly dynamic Z-disc protein immobilized by Xin and Xirp2

8 Luther P.K. Evidence that h-zone width in vertebrate muscle sarcomere is quantised in steps of $43 \mathrm{~nm}$.

9 Mártonfalvi Large-scale molten-globule dynamics contribute to titin contractility.

10 Mártonfalvi Low-force structural transitions in single titin Zs. molecules reflect a memory of contractile history.

11 Marttila M. Actin and tropomyosins show different binding affinities to mutant nebulin in vitro.

12 Müller A. E. Exercise modifies titin phosphorylation and reduces cardiac myofilament stiffness. 
13 Orfanos Z. Xin repeat proteins interact with SH3 domains of nebulin and nebulette during myofibril formation and remodeling.

14 Ottenheijm C. A. C.

Deleting exon 55 from the nebulin gene induces severe muscle weakness in a mouse model for nemaline myopathy.

15 Rudolph F. Live imaging of titin in sarcomere assembly and disassembly.

16 Sarparanta J. Characterization of CAPN3-dependent proteolysis of C-terminal tintin.

17 Schöck F. The nebulin family protein Lasp regulates thin filament length in myofibrils.

18 Siebrecht S. Ultrastructural localisation of titin during sarcomere assembly in regenerating vertebrate skeletal muscle after intoxication with notexin.

19 Suhr F

The type of chronic in vivo mechanical loading of rat skeletal muscles induces alterations of extracellular matrix structural constituents.

\section{Session VI. Diaphragm physiology}

\# Presenter Title

1 Corpeño R. Sparing of muscle mass and function by passive loading in an experimental intensive care unit model.

2 Ferreira L. F. Diaphragm contractile dysfunction in heart failure: role of the $\mathrm{p} 47^{\text {phox }}$ subunit of NADPH oxidase.

3 Hees van J. Hypercapnia attenuates ventilator-induced diaphragm atrophy and modulates dysfunction.

4 Joureau B. Diaphragm muscle weakness in a novel mouse model for nebulin-based nemaline myopathy.

5 Marques M. Diaphragm degeneration aggravates cardiac muscle injury in dystrophin-deficient mouse.

$6 \quad$ Matecki S. Leaky ryanodine receptors contribute to diaphragmatic muscle weakness during mechanical ventilation.

7 Mosqueira M. Nitric oxide modifies force production and fatigue response in diaphragm strips from $m d x$ mice.

8 Ogilvie H. Combined effects of Controlled Mechanical Ventilation (CMV) and aging on rat diaphragm muscle single fibers.

$9 \quad$ Smith I. J. Inhibition of Janus kinase signaling prevents mechanical ventilation-induced diaphragm atrophy and dysfunction.

Session VII. Muscular dystrophies and congenital myopathies

\# Presenter Title

1 Bardswell S. Myocyte contractile function in tetralogy of C. fallot.

2 Bartels B. Cardiopulmonary exercise testing in ambulatory children with Duchenne and Becker Muscular Dystrophy.

3 El-Mezgueldi Skeletal muscle myopathy mutations in M. tropomyosin gene TPM3 affect thin filament transitions between the inactive and active states.

Multimodal MRI and ${ }^{31} \mathrm{P}-\mathrm{MRS}$ investigations of the ACTA1 (Asp286Gly) mouse model of nemaline myopathy provide evidence of impaired in vivo muscle function, altered muscle structure and disturbed energy metabolism.

Habers G. E. A.

6

Harandi V. M.

$7 \quad$ Hiller $\mathrm{M}$.

Hoogaars W. Antisense oligonucleotide-mediated M. H. knockdown of TGF- $\beta$ /myostatin type I receptors as a potential therapy for duchenne and other muscular dystrophies.

9 Kintakas C. Expression of ADAMTS5 in mdx mice throughout pathology.

10 Kosá M

SERCA1b expression in human neonatal muscles and human dystrophic muscle diseases.

11 Kreissl M. Single muscle fibre mechanical studies give insight into the molecular mechanism of muscle weakness in patients with tropomyosin myopathy.

$12 \mathrm{Li} \mathrm{M}$

Muscle dysfunction and structural defects of dystrophin-null Sapje mutant zebrafish larvae are rescued by ataluren treatment.

Lindqvist J. Viral gene delivery restores muscle function in a mouse model of nemaline myopathy.

Marques M

Proteomic profile of dystrophic skeletal muscles: new potential biomarkers and drug targets for dystrophinopaties.

15 Papadaki M. Tropomyosin mutations that cause gain of function in skeletal muscle diseases.

Piers A. T.

Extracellular matrix re-modelling during regeneration in normal and dystrophic skeletal muscle.

Redowicz M. Mutation in BAG3 results in severe J. myofibrillar myopathy and Z-disc disintegration.

Rysev S. A. The effect of the Glu41lys mutation in $\beta$-skeletal tropomyosin on its position on the thin filament and flexibility during the ATPase cycle.

$$
\text { H. }
$$

Distal arthrogryposis-associated Arg91Gly mutation in $\beta$-tropomyosin induces the structural changes in the thin filaments during the ATPase cycle.

Spitali P

DMD transcript imbalance regulates dystrophin levels.

21 Tajsharghi $\mathrm{H}$. The cause of developmental myopathy due to the embryonic myosin heavy chain Thr178Ile mutation. 
23 Vignier N. Slow type fiber phenotype is involved in skeletal muscle dysfunction in an EDMD mouse model.

24 Vihola A. Novel ANO5 antibodies reveal protein defects in anoctaminopathy patients.

25 Winter de J. Force-sarcomere length relations in patients M. with thin filament myopathy caused by mutations in NEB, ACTA1, and TPM3.

\section{Session VIII. Smooth Muscle}

\# Presenter Title

1 Ardestani M. Elusive role of synaptopodin 2 in smooth

$$
\text { A. muscle cell phenotype switch. }
$$

2 Boldyreva M. Gene therapy by recombinant plasmid with A. human nerve growth factor gene stimulates angiogenesis and restoration of blood flow in ischemic murine hind limb.

3 Szekeres S. Correlation between contractile kinetics and energy metabolism in smooth muscle tissues.

Tuesday September 24, 2013

\section{Session IX. Mutations in inherited cardiomyopathies}

\# Presenter

Title

1 Bennett H. J. Unraveling the role of junctophilin-2 for stabilizing the cardiac dyadic cleft and the effects of single point mutations identified in patients with hypertrophic cardiomyopathy.

2 Colman M. A. HCN and SCN5a channel mutations: implications for impaired atrioventricular nodal conduction in heterogeneous computer models of the rabbit and mouse heart.

3 Colman M. A. Pro-arrhythmic effects of KCNA5 mutations: insights from the $3 \mathrm{D}$ virtual human atria.

4 Cramer C. E. Stress-induced troponin rise in patients with hypertrophic cardiomyopathy: associations with sarcomere mutation and MRI characteristics.

5 Jeong $\mathrm{J}$

$6 \quad$ Kraft T.

Isolated dilated cardiomyopathy with dyspnea in the patient with dystrophin gene mutation.

How can diverging functional effects of myosin mutations in FHC induce a similar disease phenotype?

$7 \quad$ Kulozik F. P. $\quad \mathrm{Ca}^{2+}$-homeostasis in ventricular cardiomyocytes and atria from transgenic mice carrying the

FHC-linked deletion mutation cTNI- $\Delta \mathrm{k} 184$

8 Kuster D.W.D. Most prevalent hypertrophic cardiomyopathy associated $M Y B P C 3^{\triangle C l O}$ mutation causes contractile dysfunction in vitro.

9 Marston S. B. Mutations in giant sarcomeric proteins discovered by whole exome sequencing of heart tissue from patients with familial DCM.

10 Messer A. E. The effects of the $\mathrm{Ca}^{2+}$-sensitiser EMD57033 on cardiac muscle contractility parallel HCM-causing mutations.
11 Möhner D.

Effects of $\beta$-adrenergic signalling on myofybrillar $\mathrm{Ca}^{2+}$-sensitivity and relaxation kinetics in a mouse model of FHC carrying the mutation $\mathrm{cTnI}^{\Delta \mathrm{K} 184}$.

12 Najafi A.

High passive cardiomyocyte stiffness in a mouse model of hypertrophic cardiomyopathy.

13 Nijenkamp L.A.M.

Altered passive tension in $\mathrm{HCM}$ with MYBPC3 mutations.

14 Novak S. M.

Role of fragile $\mathrm{X}$ proteins in the heart.

15 Pinter K

Localisation of AMPK $\gamma$ subunits in cardiac and skeletal muscles.

16 Regan J.

Altered passive stiffness in human FHC with missense or truncation MYBPC3 mutations.

17 Robinson P

Cardiomyopathy-causing mutations in cardiac thin filament regulatory proteins acutely affect $\mathrm{Ca}^{2+}$-buffering and $\mathrm{Ca}^{2+}$ dependent signalling in situ.

Low expression of the Tnnt 2 mutation $\mathrm{K} 280 \mathrm{~N}$ increases myofilament $\mathrm{Ca}^{2+}$. sensitivity in human cardiomyocytes.

19 Stehle R

$\mathrm{Ca}^{2+}$-binding to both regulatory sites of skeletal troponin $\mathrm{C}$ is required for inducing the regulatory switch of troponin I.

20 Steinwascher P. Phosphorylation of cardiac troponin I is altered through expression of HCM-mutant cTnI-R145G.

21 Tosi B

Steady state and short-term interval force relationship in ventricular trabeculae from $\triangle 160 \mathrm{E}$ and E163R cTnT mutant mice.

Turtle, C. W. R299Q AMPK $\gamma 2$ knock-in mouse model exhibits increased $\mathrm{Ca}^{2+}$-sensitivity of cardiac activation and enhanced cardiomyocyte contractility

Vikhorev P. G. DCM-causing mutation e361 $\mathrm{g}$ in actin slows myofibril relaxation kinetics and uncouples myofibril $\mathrm{Ca}^{2+}$-sensitivity from protein phosphorylation.

24 Werkman Ch. Optical trapping directly reveals a 3-fold increase in head stiffness by the FHCrelated $\mathrm{R} 723 \mathrm{G}$ mutation in the $\beta$-cardiac myosin heavy chain.

25 Wilkinson R. The DCM-causing mutation actc E361G blunts the response to adrenergic stimulation and predisposes towards heart failure under chronic stress in a transgenic mouse.

26 WitjasPaalberends cardiomyopathy depends on the location of E.R. the mutation in the gene encoding myosin heavy chain.

\section{Session X. Regulation of cardiac muscle contraction in health and disease \\ \# Presenter Title \\ 1 Amat- Molecular model confirms differences in helical Roldan I. pitch of peptides in subfragment S2 of cardiac myosin isoforms and mutations.}


2 Dijk van S. J. The functional significance of the prolinealanine and $\mathrm{C} 1$ regions of $\mathrm{CMYBP}-\mathrm{C}$ in the timing of cardiac contraction in vivo.

3 Eif van Numbers of intrinsic cardiac adrenergic cells in V.W.W. rat heart: effect of hypertrophy.

4 Holohan S-J. Does inorganic phosphate inhibit cardiac myofibrillar force production at $37^{\circ} \mathrm{C}$ ?

$5 \quad$ Kaschel L.- Cardiac and skeletal muscle protein isolation M. from zebrafish for in vitro motility assay.

6 Kopylova G. Effects of cardiac myosin binding protein-C on V. the mechanical interaction of cardiac isomyosins V1 and V3 with actin filament in an in vitro motility assay and optical tweezers.

$7 \quad$ Krijnen P. Patients with lymphocytic myocarditis A. J. have increased lymphocytes in the skeletal muscle: a new diagnostic tool.

8 Krobert K. PDE3 inhibition by levosimendan is sufficient A. to account for its inotropic effect in failing human heart.

9 Krobert K. Inactivation of inhibitory $G$ protein $\left(G_{i}\right)$ A. regulates receptor independent adenylyl cyclase activity increasing ventricular contractility.

10 Mosqueira Effects of nitric oxide (NO) on $\mathrm{Ca}^{2+}$-transients M. recorded as fluo-4 signal from electrically driven in isolated murine cardiomyocytes.

11 Nagy L. $\quad \mathrm{Ca}^{2+}$-sensitizing effects of OR-2828 in permeabilized cardiomyocytes.

12 Nikitina L. Study of effects of tropomyosin isoforms on the V. regulation of actin-myosin interaction in myocardium with in vitro motility assay.

13 Pinali C. 3D reconstruction of subsarcolemmal sarcoplasmic reticulum of sheep cardiac myocytes using serial block face SEM.

14 Rain S. Molecular determinants of increased right ventricular cardiomyocyte stiffness.

15 Rodrigues P. Myofilament changes in doxorubicin-induced dilated cardiomyopathy.

16 Torre I. Effect of myosin binding protein-c phosphorylation on ultrastructure of cardiac muscle.

17 Vasilyeva A. Different vulnerability of subendocardial and subepicardial myocytes to arrhythmia.

18 Wijnker P. A study of a novel phosphorylation site J. M. (Ser198) on cardiac troponin I.

Session XI. Muscle physiology: extreme functional demands

\section{\# $\quad$ Presenter Title}

1 Aqqad H. Effects of the intensive care unit condition on craniofacial vs. limb muscle gene and protein expression.
2 Bodnár D. Effects of selenium on the contractile properties of mouse skeletal muscles.

3 Bogaards MAO-A inhibition reduces basal oxygen S.J.P. consumption and restores isoprenaline sensitivity of hypertrophied rat papillary muscle in vitro.

4 Bogaards Demonstration of hypoxia in rat papillary S.J.P. muscle using pimonidazole.

5 Caterini J. Sigmoidal characterization of blood oxygen level dependent (BOLD) magnetic resonance imaging recovery in skeletal muscle following exercise.

6 Karatzaferi Observations on 'uremic' muscle: effect of $\mathrm{pH}$ C.

7 Larsson L. "Mechanical silencing". A primary trigger of critical illness myopathy in intensive care unit patients: experimental and clinical studies and effects of mechanical loadiong.

8 Lewis $\mathrm{P}$

Chronic hypoxia induces oxidation of proteins central to many homeostatic processes in mouse diaphragm muscle.

9 Mitrou G. I. Observations on the effect of uremia on isometric force.

10 Pauly M. Pharmacological AMPK-activation improves skeletal muscle mitochondrial function and muscle endurance in aged myostatin ko mice.

11 White G. E. A comparison of inflammatory and functional effects of different cold-water immersion protocols for recovery from high-intensity sprint exercise.

Session XII. Mitochondrial function in health and disease

\# Presenter Title

1 Cornachione Contractile properties of skeletal muscle A. S. myofibrils isolated from mice with impaired activity of the enzyme arginyl transferase (ATE 1).

2 Maughan D. Efflux measurements of endogenous proteins W. from rabbit skinned muscle fibers provide evidence of muscle glycolytic enzyme complex dissociation.

3 Poulianiti K. Observations on the effects of uremia on redox P. status.

4 Revnic C. R. The impact of oxidative stress upon physiological parameters and proton transverse relaxation times in aging rat heart.

5 Sorato E. Role of oxidative stress induced by monoamine oxidases in myoblasts of patients with collagen VI myopathies. 